\title{
8
}
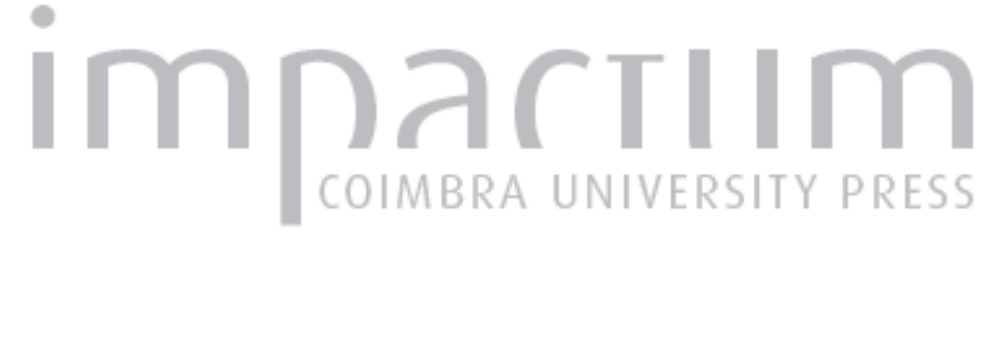

\section{A problemática do surgimento da vida humana no Comentário Jesuíta Conimbricense ao "de Anima" de Aristóteles}

Autor(es): $\quad$ Camps, Maria da Conceição

Publicado por: Faculdade de Letras da Universidade de Coimbra, Instituto de Estudos

URL

persistente: Filosóficos

DOI: DOI:http://dx.doi.org/10.14195/0872-0851_37_9

Accessed : $\quad$ 26-Apr-2023 06:44:41

A navegação consulta e descarregamento dos títulos inseridos nas Bibliotecas Digitais UC Digitalis, UC Pombalina e UC Impactum, pressupõem a aceitação plena e sem reservas dos Termos e Condições de Uso destas Bibliotecas Digitais, disponíveis em https://digitalis.uc.pt/pt-pt/termos.

Conforme exposto nos referidos Termos e Condições de Uso, o descarregamento de títulos de acesso restrito requer uma licença válida de autorização devendo o utilizador aceder ao(s) documento(s) a partir de um endereço de IP da instituição detentora da supramencionada licença.

Ao utilizador é apenas permitido o descarregamento para uso pessoal, pelo que o emprego do(s) título(s) descarregado(s) para outro fim, designadamente comercial, carece de autorização do respetivo autor ou editor da obra.

Na medida em que todas as obras da UC Digitalis se encontram protegidas pelo Código do Direito de Autor e Direitos Conexos e demais legislação aplicável, toda a cópia, parcial ou total, deste documento, nos casos em que é legalmente admitida, deverá conter ou fazer-se acompanhar por este aviso. 


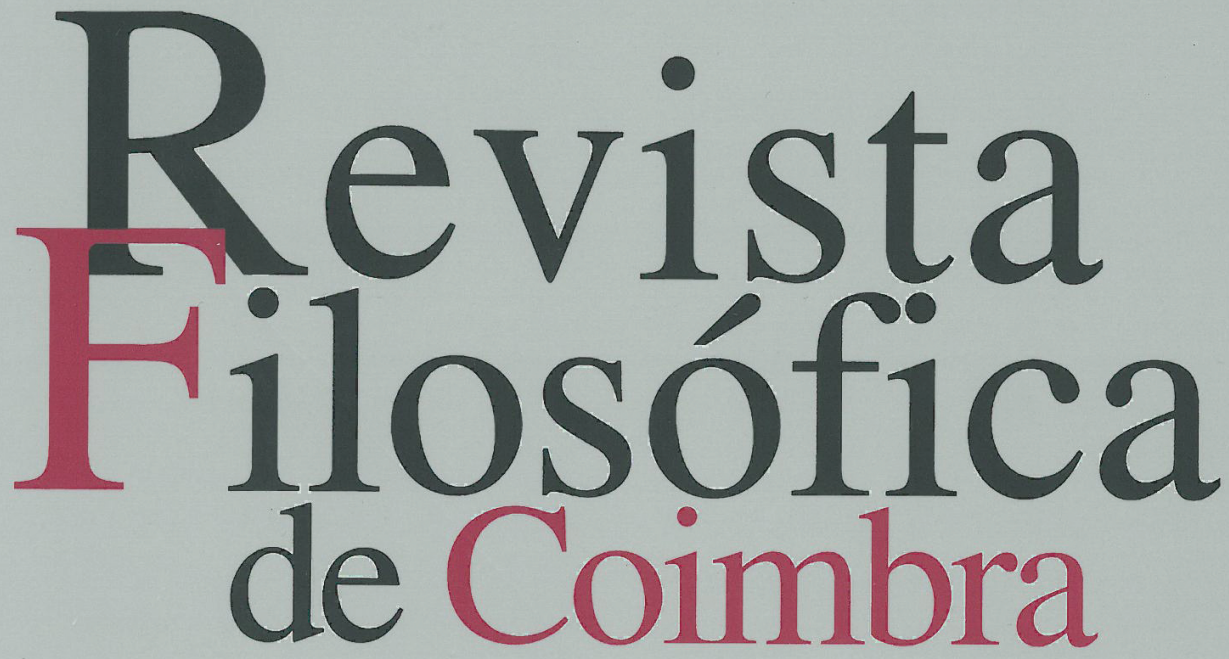

vol.19|n. $.37 \mid 2010$

Maria Luísa Portocarrero Mário Santiago de Carvalho Alexandre Franco de Sá Luís António Umbelino Luís G. Soto José Filipe Silva Joaquim Braga Maria da Conceição Camps Pedro Miguel Panarra Immanuel Kant 


\title{
A PROBLEMÁTICA DO SURGIMENTO DA VIDA HUMANA NO COMENTÁRIO JESUÍTA CONIMBRICENSE AO «DE ANIMA» DE ARISTÓTELES
}

\author{
MARIA DA CONCEIÇÃO CAMPS*
}

\begin{abstract}
Resumo: O comentário Jesuíta Conimbricense ao 'De Anima' de Aristóteles (século XVI) discute a problemática do surgimento da vida humana dando relevo, tal como hoje, no campo da bioética, aos conhecimentos mais modernos, mas manifestando também as mesmas perplexidades, nomeadamente em torno da dificuldade subjacente à definição de ser humano, cerne da antropologia filosófica. Este artigo persegue sobretudo o "thesaurus" argumentativo que entrelaça o tema anunciado pelo título com o da origem da alma intelectiva.
\end{abstract}

Palavras-chave: Aristóteles, Conimbricenses, Tomás de Aquino, Antropologia, alma intelectiva.

Abstract: The Jesuit Commentary on Aristotle's 'De Anima (16 ${ }^{\text {th }}$ century) aims at studying the origin of the human life by paying attention mainly to the argumentation developed by the authors both to that particular topic and that of the origin of the intellective soul. Not only, it is claimed, such topics are relevant to the Philosophical anthropology but also they are illuminating as regards today's bioethical discourse.

Key Words: Aristotle, Conimbricenses, Thomas Aquinas, Anthropology, intellective soul.

No texto que iremos abordar, a problemática antropológica do nascimento do ser humano entrelaça duas temáticas que aqui nos proporemos

\footnotetext{
* Gabinete de Filosofia Medieval (Faculdade de Letras da Universidade do Porto).
} 
explicar, a da origem da alma intelectiva e a do início da vida humana ${ }^{1}$. Embora tratando-se de um comentário a Aristóteles, o Comentário Jesuíta Conimbricense ao "De Anima" vai mais longe do que o texto comentado, no capítulo da definição da alma dada pelo Estagirita. Ao adiantar-se na discussão, procura, à luz do seu tempo, responder aos problemas que se deviam colocar no domínio da filosofia e da ciência dos finais do século XVI, chamando à colação filósofos e teólogos antigos e coevos. É de realçar, que o Cursus Conimbricensis do Colégio Jesuíta consubstanciava um modelo de ensino, a todos os títulos, antecessor do que viria a ser o ensino secundário em Portugal e na Europa, destinando-se a jovens que pretendia formar nos diversos domínios do saber, mas de um saber profundamente implicado no mundo e na História, de acordo com o projecto da Companhia de Jesus, nos campos do ensino e da missionação. A sua actualização revela-se, muito especialmente, nas metodologias pedagógicodidácticas utilizadas e no recurso às fontes. Havia que responder a problemas de ordem prática desencadeados pela descoberta de novos mundos, empreender a Contra Reforma. Tal exigia uma preparação cuidada para a acção, onde o papel da argumentação adquiria uma nova pujança, enquanto poderoso meio de evangelização e de defesa da fé católica face aos ataques dos Reformadores. Neste Comentário está patente um autêntico thesaurus argumentativo e o tema que seguidamente trataremos é disso um significativo exemplo.

Privilegiando a concepção aristotélica de alma como enteléquia do corpo (De Anima II $412^{\mathrm{a}} 18-21$ ), começa por inquirir se todas as faculdades da alma o são. Concluindo que a alma é enteléquia de certas partes do corpo, subsistindo uma parte da alma intelectiva que pode existir separada, dada a sua incorruptibilidade, remete a análise desta última para o Apêndice a este volume do Cursus (Tractatus de anima separata). No entanto, a discussão sobre a origem da alma intelectiva e sobre o momento em que é incorporada no feto, tem lugar no Comentário ao De anima, Livro II.

Propomo-nos analisar esta discussão, dada a pertinência e oportunidade da mesma, tendo em conta que, segundo a concepção defendida, ela coincide com o início da vida humana. Pretendemos, assim, realçar a actualidade das problemáticas analisadas nesta obra portuguesa do século XVI, evocando alguns posicionamentos recentes no domínio da bioética, procurando manter a atitude científica subjacente à do Cursus, que encetou uma dialogia entre autores de diferentes tempos e lugares, no que respeita a algumas perplexidades que acompanham o fenómeno humano. Se é um

1 Comunicação apresentada ao "Congresso Internacional Pessoa e Sociedade: Perspectivas para o século XXI," Faculdade de Filosofia de Braga, Braga, 16-18 de Outubro de 2005. 
facto, que do ponto de vista puramente teórico, a posição adoptada em pouco ou nada difere da de São Tomás, assistimos contudo, a um tipo de fundamentação e de argumentação destinadas a responder aos novos problemas do homem do Renascimento, já que, ao recolocá-lo no centro do universo, havia que redefinir o que é ser humano, redireccionando uma antropologia. É neste sentido que, quanto a nós, deve ser compreendida a discussão em torno da incorporação da alma intelectiva no feto e o consequente nascimento do homem.

\section{A Origem da Alma Intelectiva}

O início do Comentário ao Livro II do De Anima, remete-nos para a discussão do conceito de alma proposto por Aristóteles. Reproduzamos uma paráfrase do texto2:

A alma é o acto primeiro substancial de um corpo orgânico que tem a vida em potência. "Primeiro", para rejeitar os actos segundos, sobretudo as operações; "substancial", para afastar os actos acidentais; "do corpo", para excluir as substâncias separadas que não assentam nos corpos e os princípios dos orbes celestes; "de um corpo orgânico, que tem a vida em potência", ou seja, em que a matéria está afecta aos órgãos em ordem a executar as funções vitais, que se encontra apto a receber a forma, afastando desde logo da definição, as formas naturais indistintas (como a pedra ou o fogo) e os corpos dos cadáveres.

${ }^{2}$ Commentarii Colegii Conimbricensis In tres libros de Anima Aristotelis Stagiritae Conimbricae 1592 (doravante: Commentarii...) II c., q.1, a.1, p.32: “Anima est actus primus substantialis, corporis organici, potentia uitam habentis. Quae membratim sic explicanda erit. Dicitur anima, actus enteleceia, ita late accepto uocabulo ut tam actus substantiales, quam accidentarios comprehendat sicut annotauimus in contextu. Ponitur ergo actus ad excludendam materiam primam, quae est pura potentia, et quaecumque non sunt simpliciter actus, ut composita tam naturalia, quam artificialia. Primus, ad reiiciendos actus secundos, praecipue operations (...). Substantialis, ad ad remouendos actus primos accidentarios, ut potentias respectu suorum actuum. Corporis, ad excludendas, tum substantias separatas, quae corporibus non assident: tum etiam mentes coelestium orbium motrices, quae non sunt actus corporum coelestium, quasi ea proprie informent: etsi eis assideant: quanquam secus arbitrati fuerint nonnulli, quos alibi confutauimus. (...) Sequitur in definitione, organici, potentia uitam habentis, quae duo idem ualent, ut aduertit Themistius, Alexander, Philoponus, D. Thomas et alii: quanquam Simplicius aliter sentiat. Excluduntur autem hisce uerbis a definitione animae omnes formae naturales, quae per superiores particulas nondum reiectae fuerant, ut formae lapidis et ignis: quarum corpora, siue ut proprie loquamur, materiae ad exercenda uitae munia organis, siue intrumentis distinctae non sunt. Inter quas etiam numerantur formae cadauerum. Nam oculi, pedes, 
Depois de discutir os argumentos dos opositores da definição anteriormente proposta, de Aristóteles, designadamente os de São Nemésio, São Gregório de Nissa, Justino Mártir, Galeno, de alguns antigos como Dinorco, Empédocles e Aristoxeno (c.I, q.1, a.2), o texto nega, no artigo seguinte, a composição da alma. Por muitas razões, entre as quais porque o composto é acidente e a alma é forma do corpo, recebendo através dela o ser, e cada ser vivo é substância composta de forma e de matéria. Prova, a seguir, a substancialidade da alma intelectiva:

Mas prova-se particularmente que a alma intelectiva é substância, porque de outro modo não poderia continuar, por si, para além da matéria e, portanto, não seria imortal, o que não só repugna à divina fé, mas também às leis da filosofia, como claramente defendemos no Tractatus de anima separata. ${ }^{3}$

A alma intelectiva é uma substância que não é nem matéria nem corpo (c.I, q.1, a.5). Não é matéria porque a matéria é pura potência, está privada de actividade e a alma é origem e fonte das operações vitais. Não é corpo, de entre outras razões (ibidem), porque move o corpo, insinuando-se por todo o corpo, que é movido, sendo a sua forma e princípio do movimento. A alma intelectiva é, por fim, substância espiritual, englobando em si o intelecto e a vontade.

A nossa conclusão prova-se assim. Cada coisa é tal como opera. Mas a alma intelectiva tem operações elevadas acima da natureza e da condição do corpo e da matéria. Prova-se a menor, quer da parte do intelecto, quer da parte da vontade. Da parte do intelecto, porque o nosso intelecto percebe as naturezas comuns e abstractas a partir da matéria singular (...) Do mesmo modo, o nosso intelecto forma os conceitos das coisas imateriais, como o de Deus e o das substâncias separadas e percebe tais objectos livres de toda a dimensão, sem formato, cor e outras afecções da massa corpórea. Mas estes conceitos não são materiais, têm, portanto, origem na potência e na forma imaterial. Esta é a alma intelectiva. ${ }^{4}$

manus, aliaque id genus instrumenta quae in iis apparent, non uniuoce, sed analogice duntaxat cum organis uiuentium conueniunt, ut Aristoteles hoc primo capite textu nono et libro septimo Metaphysicorum capite 10. textu 35. docet." Todas as traduções são da nossa responsabilidade.

${ }^{3}$ Commentarii... II c.1, q.1, a.4, p.39: "Priuatim autem quod anima intellectiua sit substantia, ex eo conuincitur, quia alioqui non posset extra materiam per se cohaerere, atque adeo non esset immortalis; quod non solum diuinae fidei, sed etiam Philosophiae decretis repugnat; ut in Tractatu de anima separata ex professo ostendemus."

${ }^{4}$ Commentarii...I, c.1, q.1, a.6, p.41: "Probatur autem nostra conclusio hunc in modum. Vt unumquodque, operatur, ita est: sed anima intellectiua habet operationes eleuatas supra naturam et conditionem corporis ac materiae: ergo anima intellectiua non est materialis et 
Opõe-se depois às heresias de Gnósticos, Maniqueus e Priscilianistas, de entre outros, que defendiam que a alma é partícula da mente divina, citando as condenações que o Concílio de Braga fez destas posições, bem como as de Santo Agostinho, São Crisóstomo, Santo Atanásio e São Tomás (c.I, q.1, a.6).

A Questão II é inteiramente dedicada à problemática da subsistência da alma intelectiva e a Questão III à sua origem divina. São refutadas, por isso, as posições dos Luciferianos, Tertuliano e Apolinário, que afirmaram que a alma intelectiva se reproduz a partir do sémen, e também as daqueles, como Avicena, Seleuco e Jeremias e também Galita (donde nasceria a heresia dos Messalianos), que consideraram que as almas intelectivas foram criadas pelas inteligências, não por Deus. Rejeita, que as almas racionais se propagam pela potência seminal, na esteira de Santo Agostinho e de São Tomás. Conclui pela superioridade da alma intelectiva:

Nenhuma potência activa age para além do seu género, mas a alma intelectiva excede todo o género de natureza corpórea, visto que é substância espiritual, como acima mostrámos. Portanto nenhuma potência corpórea pode conseguir a sua produção, porém toda a faculdade seminal existe a partir da potência corpórea, já que respeita à potência vegetativa, inteiramente inerente ao corpo. Portanto, não é possível que as almas intelectivas sejam derivadas da potência seminal. ${ }^{5}$

Perfilhando a posição de São Tomás ${ }^{6}$, adianta outras razões, como a da subsistência fora do corpo e o facto de possuir uma origem não natural (c.I, q.2, a.2), afastando a hipótese da criação angélica (c.I, q.2, a.3), e concluindo que Deus cria as almas intelectivas à medida da geração dos corpos.

corporea, sed immaterialis substantia, seu spiritus. Probatur minor tum ex parte intellectus, tum ex parte uoluntatis. Ex parte intellectus, quia intellectus noster percipit naturas communes, et abstractas a materia singulari: quod uero materiale est, ut est crassum et limitatum, ita nonnisi singulare corporeum et materiale apprehendit. Item noster intellectus format conceptus rerum immaterialium, ut Dei et substantiarum separatarum percipitque talia obiecta omni dimensione libera, sine figura, colore, aliaue corporeae molis, affectione hi autem conceptus, materiales non sunt oriuntur ergo a potentia et a forma immateriali: haec est anima intellectiua: igitur anima intellectiua est immaterialis substantia, siue spiritus.»

${ }^{5}$ Commentarii...II, c.1, q.3, a.2, p. 55: «Probatur igitur nostra assertio hunc in modum. Nulla uirtus actiua agit ultra suum genus; sed anima intellectiua excedit totum genus corporeae naturae, cum sit substantiae spiritalis, ut superius ostendimus. Nulla igitur uirtus corporea eius effectionem ualet attingere; atqui omnis actio seminalis facultatis, est a uirtute corporea; cum spectet ad potentiam uegetatricem corpori prorsus inhaerentem. Ergo fieri non potest, ut animae intellectiuae uirtute seminis deriuentur.»

${ }^{6}$ Cf. Tomás de Aquino, Contra Gentes II, c. 87; Id., Summa Theologiae Ia , q. 118. 


\section{O momento da infusão da alma no feto}

Começando por explicar de que modo a matéria do feto se desenvolve em ordem à recepção da alma intelectiva, o Comentário critica o erro dos que consideram que a alma não é introduzida no feto senão depois de ter sido dado à luz. Também o de Alexandre de Hales, ao afirmar que as funções da vida que aparecem no embrião não existem a partir da sua alma, mas que são derivadas ou da alma da mãe ou da potência formativa seminal, com base no entendimento comum dos filósofos de que as operações vitais devem porvir não do seu princípio exterior mas do seu princípio interior de vida. Daí que, quando o embrião se nutre e cresce já nele exista a alma. Enumera seguidamente as posições dos que consideraram que o embrião já possui alma: uns, afirmando que no feto subsiste a alma vegetativa, a que sobrevém a sensitiva, seguida da intelectiva; outros, entendendo que não há várias almas mas apenas uma, que se transformou de nutritiva em sensitiva e, finalmente, deveio intelectiva por intervenção divina. Há ainda quem considere - prossegue o Comentário - que o feto desde o início obteve a alma intelectiva, ainda que não apreenda desde logo as funções a ela inerentes, mas primeiro as de vegetar, seguidamente as de sentir e, a seu tempo, as de inteligir. As posições anteriores (c.I, q.3,a.1) são rejeitadas e defende-se que a matéria do feto é primeiro enformada pela alma vegetativa, de seguida pela sensitiva e em último lugar pela intelectiva, fazendo coincidir a sua posição com a de São Tomás ${ }^{7}$ :

Assim, conquanto o feto permaneça na matéria alguns dias, sob a forma vegetativa, a seguir a esta intervenção sucede a forma sensitiva e, do mesmo modo, a esta, a intelectiva. Não admira que as duas primeiras não se extingam por nenhum ataque ou embate de inimigo externo. Na verdade, como a primeira é via ou preparação para a segunda e a segunda para a terceira, as duas primeiras recebem na matéria as disposições que mantêm somente durante certo espaço de tempo, dando lugar à forma principal, à qual precedendo, servem deste modo de guardiãs. Que a alma intelectiva não enforma imediatamente, desde o princípio a matéria do feto, amplamente o demonstram alguns decretos dos Cânones sagrados que acrescentam o seguinte, e omitindo aqui o restante, no capítulo Sicuti 32, questão 2, quando se diz que não é cometido homicídio por aquele que mata no útero o feto antes da infusão da alma, isto é, da alma racional, porque ainda não se pode dizer que nasceu o homem. ${ }^{8}$

${ }^{7}$ Cf. Tomás, Suma Teológica, I Parte, q. 76, a. 3 ad 3 um e q. 118, a. 2 ad 2 um.

${ }^{8}$ Commentarii...II, c.1, q.4, a.2, p.63: "Ita porro manet foetus materia aliquot diebus sub forma uegetatiua: deinde huic intereunti succedit forma sensitiua, similiterque huic intellectiua. Nec mirum, quod duae priores formae nullo externi hostis incursu, aut 
Repete pois que, no início, o embrião tem uma alma só sensitiva a que sucede outra mais perfeita, primeiro sensitiva, depois intelectiva.

Quanto ao período de tempo que decorre entre a concepção e a perfeição exigida para a infusão da alma racional, remetendo para a noção de perfeição de corpo orgânico transmitida por Aristóteles, anuncia ser cerca de quarenta dias após a concepção do macho e de oitenta dias após a concepção da fêmea. Segundo Aristóteles, o corpo da fêmea, por falta de calor e de potência formativa seria mais lentamente delineado:

Além disso, quanto ao período de tempo (estabelecido no princípio da questão proposta) relativo ao espaço de dias em que a alma intelectiva é infundida no corpo, subsiste discussão entre os filósofos. Concordam, porém, nisto, que é infundida logo que o corpo está perfeito e distinto com órgãos apropriados à prole humana, que obtém enquanto não é do tamanho maior do que é próprio da maior formiga, como afirma Aristóteles, livro 7 De Historia Animalium, capítulo 3, e Abulense no capítulo I, de Mateus, parte I, questão 53. De facto, nem sempre o tamanho é o mesmo. Sobre este assunto Fernélio escreveu assim, no livro De hominis procreatione, capítulo 10: Muitas vezes observámos o feto abortado no quadragésimo dia, de meio dedo (como afirma Aristóteles) com o verdadeiro tamanho de uma formiga grande e inteiramente formado. A cabeça era semelhante a uma avelã, maior por relação ao restante corpo, os olhos como que descobertos por pinças, o nariz, as orelhas, os braços, as mãos, as pernas, os pés e neles, os dedos separados. Os filósofos também concordam que o corpo da fêmea por falta de calor e de potência formativa é mais lentamente delineado. No entanto, os que até então escreveram sobre este assunto, discordam sobre o tempo em que a obra está concluída sobre o esboço. (...) [T] odavia é mais comum e verdadeira a opinião de que é concluída nos machos cerca do quadragésimo dia, nas fêmeas cerca do octogésimo, o que se confirma da melhor maneira, porque na velha lei, se a mulher parisse um macho ficava em casa quarenta dias, se uma fêmea, oitenta dias, e deixava de entrar no templo. $\mathrm{Na}$ verdade, os intérpretes das palavras divinas dizem que foi prescrito este número para imitação da natureza e do tempo em que o corpo se forma no útero. ${ }^{9}$

oppugnatione, intereant. Nam cum prior sit uia seu praeparatio ad secundam et secundam ad tertiam; priores ambae eas accipient in materia dispositiones, quibus non nisi certo temporis spatio perseuerent, cedantque principi formae, cui praeeundo, istiusmodi ueluti satellitio famulantur. Sane quod anima intellectiua non statim a principio materiam foetus informet, plane ostendunt nonnulla sacrorum Canonum decreta, quae id supponunt, et ut caetera omittamus, caput Sicuti 32. quaest. 2. ubi dicitur non committi homicidium ab eo, qui foetum in utero occidit ante infusionem animae, uidelicet rationalis: quod non dum dici possit natum esse hominem.»

${ }^{9}$ Commentarii...II, c.1, q.4, a.2, p. 64: «Caeterum quo temporis puncto (quod erat propositae quaestionis caput) seu quot dierum transacto spatio anima intellectiua infundatur 
A opinião dos autores sobre o tempo de conclusão da obra é variável (c.I, q.4, a.2). O Comentário reforça a resposta dada ao mesmo tempo que admite uma excepção:

Colocadas assim as questões, respondemos à questão suscitada no início, que a alma intelectiva é infundida e unida ao corpo no instante em que, primeiro, pela matéria e pela forma dos membros e pelos restantes acidentes que tal forma exige, foi instituída e disposta, o que costuma acontecer por volta do dia que há pouco dissemos. Todavia o Corpo de Cristo, Nosso Salvador, no útero da Virgem Mãe não observou esta lei da formação sucessiva. Efectivamente, o que o período de quarenta dias, por potência da natureza deveria formar aos poucos, foi concluído em absoluto, num instante, por obra do Espírito Santo e da Potência Divina (...). ${ }^{10}$

corpori disceptatio est inter Philosophos: in eo tamen conueniunt quod infundatur cum primum corpus organis humanae proli conuenientibus distinctum, perfectumque est: quod obtinet etiam dum non est sub magnitudine maiori, quam sit grandioris formicae, ut affirmat Aristoteles lib. 7. De Historia animalium cap. 3. et Abulensis in caput 1. Matthaei parte 1. quaest. 53. Verum non semper haec magnitudo eadem est. Qua de re ita scripsit Fernelius in libro De hominis procreatione capite 10. Saepe obseruauimus die quadragesimo eiectum foetum semidigiti (ut ait Aristoteles) formicae maiusculae magnitudine uere, ac prorsus conformatum. Caput erat auelanae par, et maius, quam pro reliqui corporis ratione: oculi ut cancris exerti: nasus, auriculae, brachia, manus, crura, pedes, hisque secreti digiti: haec ille. Conueniunt quoque Philosophi in eo, quod foeminae corpus ob defectum caloris, et imbecillitatem uirtutis formatricis tardius delineetur. Quo autem tempore huiusce delineationis opificium absolutum sit, discordarunt qui olim ea de re scripserunt. Lege Plutarchum lib. 5. De placitis cap. 21. Hippocratem in lib. De foetu, Fernelium in lib. De hominis procreatione, Coelium lib. 25. Lectiones antiquae cap. 23. Ambrosium Pareum lib. 23. cap. 11. Communior tamen, ueraque sententia est, in maribus absolui circa quadragesimum diem; in foeminis circa octogesimum. Quod ex eo optime confirmatur, quia in ueteri lege foemina, si masculum pareret, quadraginta diebus; si foeminam, octoginta se se domo continebat, et a templi ingressu cessabat. Hunc enim numerum diuinarum literarum interpretes ad imitationem naturae, ac temporis, quo in utero corpus effingitur, praescriptum fuisse aiunt."

10 Commentarii...II c.1, q.4, a.2, p. 64 "Quibus ita constitutis respondemus ad quaestionem initio excitatam; animam intellectiuam infundi et uniri corpori in eo instanti, quo primum materia, et membrorum effigie, et caeteris accidentibus, quae talis forma exigit, instructa dispositaque est; quod accidere solet circa eum diem, quem diximus paulo ante. Hanc tamen successiuae formationis legem, non seruauit Corpus Christi seruatoris nostri in utero Virginis Matris. Nam quod naturae ui quadraginta dierum spatio paulatim effingendum erat, diuina uirtute, ac Spiritus Santi opera, momento perfectum absolutumque fuit, ut est communis Patrum et scholasticae Theologiae professorum doctrina." 
Podemos agora, face ao citado, colocar a questão de saber qual o estatuto ontológico do feto, segundo o Comentário, antes de perfazer o momento em que é enformado pela alma intelectiva, já que, segundo São Tomás, esta é a única forma substancial do homem que contém virtualmente a alma ${ }^{11}$, ou seja, a alma intelectiva está unida ao corpo como forma substancial, sendo impossível possuir outras formas substanciais já que esta lhe lega o ser absoluto, transformando o feto num ser humano. A alma intelectiva é criada por Deus ao completar-se a geração humana e esta alma é, ao mesmo tempo, sensitiva e vegetativa, corrompendo-se as formas que a precedem. $\mathrm{O}$ homem engendra o semelhante a si quando, por virtude da substância seminal, a matéria é disposta para a recepção da alma racional. Há portanto, segundo esta posição, geração do semelhante pelo semelhante e criação divina, no projecto humano.

Perante a descrição feita neste passo da obra, algumas constatações se nos deparam:

Primeira: a dificuldade em determinar com exactidão o momento efectivo em que o embrião/ feto devém homem, o momento em que é incorporada a alma intelectiva.

Segunda: a partir da descrição da formação sucessiva, é evidente a presença da geração e da criação num mesmo processo, num entrosamento difícil de situar no tempo e no lugar. Antes se evidencia a insuficiência e precariedade dos conceitos de corpo e de alma na definição do processo de concepção, desenvolvimento e perfeição da vida que conduz ao nascimento do homem. Da leitura atenta de todo este capítulo I, do Livro II do Comentário, ressalta a enorme dificuldade que os autores encontram em distinguir fronteiras, delimitar momentos, dificuldades estas que, em muitos casos, levam a uma explicação que verdadeiramente não o é, na tentativa de abarcar o real e de não ficar sem resposta.

Terceira: a manifesta dificuldade subjacente à posição doutrinária que define a alma intelectiva como a única forma substancial do homem e o consequente hiato existente entre o momento da concepção e o surgimento do ser humano.

Por último: Restará perguntar que ser é este que ainda não é homem, mas não é animal nem planta. A tal não é dada resposta satisfatória, mas é evidente que tal ser surge, sobretudo, como sujeito de um processo, de um dinamismo em que é definido, por tentativas, negativamente, pelo que ainda não é, mais do que por aquilo que, efectivamente é. Figura como sujeito de um processo preparatório e adequado ao projecto da criação divina da alma racional. Nele, a perfeição do corpo é guardiã da alma

${ }^{11}$ Cf. Tomás de Aquino, SumaTeológica, Iª, q. 76 a.1 e a. 4. 
racional e, uma vez incorporada esta, ela mesma absorve o que até ali ainda não era o homem, integrando-o num todo indestrutível, pela incorporação da forma substancial, da alma intelectiva. Neste sentido, todo o percurso, desde a fecundação até à incorporação da alma intelectiva e desta até ao nascimento propriamente dito, é como que um acto único diferido no tempo, já que obedece a uma mesma finalidade.

A suspensão da forma substancial, esse hiato, denota a fragilidade da explicação face à percepção da grandiosidade da obra e da sua finalidade, mas não deixa de evidenciar os novos ventos que sopravam e que exigiam uma atenção redobrada para a explicação dos fenómenos da vida nas suas várias vertentes. $\mathrm{Na}$ realidade, este ser, centro do processo de desenvolvimento da vida humana, mais se define pelo que há-de ser, ou melhor, pelo que é em interacção com o Outro/s, sejam eles os progenitores (para o ser em geração) ou Deus (para a criatura). Ressalta a dialogia, o dinamismo, a relação entre o que efectivamente é, existe, em cada momento desta etapa, e que por si só escapa a uma definição estática, e os participantes do projecto humano, geradores ou Criador. Sobressai a permanente interacção entre gerador e ser gerado, entre Criador e criatura.

Mas é evidente que o texto conclui que a verdadeira substancialidade provém da intervenção criadora, divina, através da incorporação da alma racional, isto é, no momento em que o processo de geração é como que finalizado dando lugar a um outro de natureza superior, transcendente. No entanto, o finalizar da geração coincide com a perfeição dos órgãos corpóreos, factor essencial para a recepção da alma intelectiva. Alma e corpo aparecem de tal modo interrelacionados e entrosados que somente se concebem numa relação de interdependência mútua durante todo este processo.

\section{Conclusão}

Debatemo-nos hoje com dificuldades similares às que marcaram esta obra, em particular, na abertura de caminhos novos no campo da filosofia e da ciência. Será que ainda fará sentido falar de alma e de corpo, enquanto universos separados? E de substância? Perante o surgimento de novos paradigmas, designadamente o paradigma relacional que pretende de alguma forma responder às dificuldades, que já no século XVI eram questionadas e que, cremos, continuarão a sê-lo dada a dificuldade de definição e de realização do ser humano nas vicissitudes do Tempo e da História, não queremos passar em silêncio o papel que o presente Comentário pode ter tido na abertura de novos processos, procurando dar resposta a problemas concretos que ocorriam na sociedade do tempo. 
A dificuldade subjacente à definição do que é ser homem, que hoje, talvez mais do que nunca, subsiste, mas sobretudo a tentação de delimitar momentos de ouro, fundacionais da vida humana é, também, nos nossos dias, frequente entre os investigadores da matéria, independentemente da especialidade científica a que pertençam, fazendo depender de tal momento (seja ele a incorporação da alma racional, a perfeição dos órgãos, a viabilidade pós-natal, de entre outros) todo o processo de aquisição da humanidade, colocando-o no centro da problemática da vida humana e, consequentemente, da legitimidade ou não da sua interrupção no útero materno ou ainda antes da nidação. Frequentemente esta discussão, não só esbarra na falta de resposta clara e inequívoca, como coloca os investigadores a reboque de um desenvolvimento técnico-científico que permite apurar cada vez com maior nitidez os sucessivos momentos, fracções do desenvolvimento do embrião ou do feto, em que novas aptidões e capacidades são adquiridas quer no útero, quer mesmo ainda antes do ovo nele se implantar (para já não falar das situações inerentes aos modernos processos de fecundação medicamente assistida, como a fecundação in vitro, a problemática da congelação de embriões, de entre outras, mas que ainda não foi capaz, se é que algum o dia o será, de dar a esperada resposta, provavelmente porque não há resposta para uma questão mal colocada, ou melhor, porque tal resposta não pertence ao seu domínio).

De facto, mais do que "o momento", ressalta todo um processo, todo um dinamismo que se inicia na fecundação e culmina no nascimento, independentemente da diferente valoração da dignidade social de cada uma das etapas a ele inerentes, por cada sociedade em cada tempo e lugar.

Mais do que dar uma resposta a estas questões, é de evidenciar no Comentário a preocupação pelo seu tratamento pormenorizado e relativamente aprofundado, talvez à luz de problemáticas antropológicas que de algum modo assolavam a sociedade do tempo, designadamente o papel central que o homem assume no Renascimento, os diversos "tipos de homens" recém conhecidos, com a proliferação de raças e de culturas, que levantam novas problemáticas sobre a definição de homem, a começar na imagem, passando pela diversidade de padrões culturais, de níveis de desenvolvimento, de modos de vida, de formas de olhar o mundo. A missionação jesuíta ajudou a alterar o "espelho", o Outro, em que o europeu até aí se reviu e se definiu como ser humano. Transportando a religião e o ensino desde a América do Sul até aos confins da Ásia, lá encontrou matéria para um aprofundamento da humanidade, percebendo a pluralidade do fenómeno humano. Os passos seguintes deste mesmo livro II, são disso testemunho, designadamente quando se debruçam, por exemplo, sobre a igualdade ou não das diferentes almas intelectivas e, consequentemente, 
dos homens entre si, dedicando muitas linhas a esta problemática, tornandoa actual ${ }^{12}$. É neste sentido que reforçamos o que dissemos acima, isto é, que toda a discussão presente no Cursus, sobretudo neste Comentário, é fortemente implicada no Tempo e na História, com o fim último da salvação da alma, através da valorização da humanidade em cada homem, o que passa pelo aprofundamento da reflexão sobre o que é o ser humano, redimensionando-o à luz do mundo novo que então foi dado à luz.

\section{REFERÊNCIAS BIBLIOGRÁFICAS}

Commentarii Colegii Conimbricensis In tres libros de Anima Aristotelis Stagiritae, Conimbricae, 1598.

Aristote. De l'Ame. Trad. nouvelle et notes par J. Tricot, J. Vrin, Paris, 1959.

S. Thomae Aquinatis. Summa Theologiae. Pars Prima. Ed. BAC, Madrid, $5^{\text {a }}$ ed., 1994.

ARCHER, Luís; BISCAIA, Jorge; OSSWALD, Walter; RENAUD, Michel (org.), Novos Desafios à Bioética, Porto Editora, Porto, 2001.

BASCHET, Jérôme, "La parenté partagée: engendrement charnel et infusion de l'âme (à propôs d'une miniature de la fin du XVe siècle)", in CASAGRANDE, Carla; VECCHIO, Silvana (a cura di) Anima e Corpo Nella Cultura Medievale, Edizioni Del Galluzzo, Firenze, 1999, 123-137.

CARVALHO, Mário Santiago de, "Filosofar na Época de Palestrina, uma introdução à psicologia filosófica dos "Comentários a Aristóteles" do Colégio das Artes de Coimbra", Revista Filosófica de Coimbra 11 (2002) 389-419.

DINIS, Alfredo,"O Que É Ser Humano? A Perspectiva das Ciências Cognitivas" in DINIS, A.; CURADO, J.M. (org.), Consciência e Cognição, Publicações da Faculdade de Filosofia de Braga, Universidade Católica Portuguesa, Braga 2004, 29-46.

VICO, Romana Martorelli “Anima e corpo nell' embriologia medievale, in CASAGRANDE, Carla; VECCHIO, Silvana (a cura di), Anima e Corpo Nella Cultura Medievale, Edizioni Del Galluzzo, Firenze, 1999, 95-106.

12 V.g. Commentarii...II, c.1, q.5, p. 64: Se todas as almas intelectivas são iguais em dignidade da natureza. 